\title{
Azúcar, deforestación y paisajes agroindustriales en Cuba, 1815-1926*
}

\author{
Sugar, deforestation and Cuban \\ agro-industrial landscapes, 1815-1926
}

\author{
REINALDO FUNES MONZOTE ${ }^{\star *}$ \\ Fundación Antonio Núñez Jiménez de la Naturaleza y el Hombre \\ Profesor Adjunto, Universidad de La Habana \\ gponjuan@infomed.sld.cu
}

\begin{abstract}
RESUMO Entre 1815 y 1926 los paisajes cubanos sufrieron una gran transformación como consecuencia de la expansión de la industria azucarera por sus regiones naturales llanas y alomadas, cuyo resultado más visible fue la rápida deforestación para satisfacer las necesidades de tierras fértiles, combustible y maderas de construcción. Este trabajo ofrece una visión general de ese proceso, que se caracterizó por la coincidencia de dos factores decisivos: la concesión a los particulares del derecho absoluto a talar los árboles dentro de sus propiedades y la introduc-
\end{abstract}

\footnotetext{
Artigo recebido em: 09/11/2004 - Aprovado em: 27/11/2004.

* Agradezco a Regina Horta por invitarme a participar en este número. Una versión anterior de este trabajo fue presentada en la conferencia anual del 2004 de American Society for Environmental History (ASEH), en Victoria, Canadá. A John Soluri mi agradecimiento por incluirme en la mesa redonda: "Voices (Not) in the Wilderness: New Perspectivas on Latin American Landscapes" y a ACLS/SSRC Working Group on Cuba y ASEH por los recursos facilitados para el viaje y la estancia. Para la investigación he contado con el apoyo del proyecto de investigación BHA2002-02031 del Ministerio de Ciencia y Tecnología, España.
} 
ción de los avances tecnológicos de la era de la revolución industrial en la producción de azúcar.

Palavras-chave agroindústria açucareira cubana, paisagens cubanas, história de Cuba

ABSTRACT Between 1815 and 1926, Cuban landscapes went through great transformations as a result of the sugar industry's expansion into its natural regions. The most visible result was a rapid deforestation giving way to the needs for fertile and combustible lands and wood for construction. This paper offers a general view of this process, which is characterized by the coincidence of two decisive factors: the concession to private individuals of the absolute right to fell trees within their properties and the introduction of technological progress from the industrial revolution era in sugar production.

Key words Cuba's sugar agroindustry, Cuban landscapes, Cuban history

... si se exceptúan 14 o 16 leguas de contorno de La Habana y algunos pocos paños más de tierra, como en Villa Clara, pueblo dado a la agricultura, otros muy contados para ingenios, y los pastaderos de ganados, llamados sabanas que son las desmontadas, todo el resto viene a ser un fragoso bosque.

Joaquín de Ozes y Alzua, $1794^{1}$

Al viajar a través de las provincias al este de La Habana luce que la isla constituye un inmenso campo de caña. En muchos lugares aparecen campos sin interrupción alguna, que se extienden a través de la llanura hasta el horizonte. Se observará algún tabaco y lotes de maíz, plátanos, frijoles, yuca, boniatos, malangas y otros vegetales, y pequeñas arboledas de aguacates y mangos, pero estos generalmente serán borrados del cuadro mental agrícola por la enormidad y ubicuidad de los campos de caña.

Hugh H. Bennett y Robert.V. Allison, $1928^{2}$

1 OZES Y ALZUA, Joaquín de, "Representación hecha al Consejo de Indias sobre el remedio que necesita el nuevo obispado de Cuba para su fomento dirigida por su obispo en 30 de noviembre de 1794", en AGUIRRE, Ana Irisarri, El Oriente cubano durante el gobierno del obispo Joaquín de Osés y Alzúa (1790-1823), EUNSA, Ediciones de la Universidad de Navarra, Pamplona, pp. 329-359. Se basaba en su experiencia con motivo de haber atravesado la Isla desde La Habana hasta Santiago de Cuba en 1789.

2 BENNETT, Hugh H. y ALLISON, Robert.V., Los suelos de Cuba, La Habana, Comisión Nacional Cubana de la UNESCO, 1962. Primera edición, en inglés, en 1928. 


\section{Introducción}

A mediados del siglo XIX el naturalista español Ramón de La Sagra cuestionaba si la destrucción de los bosques de Cuba sería inofensiva para la conservación de las admirables condiciones de fertilidad de la Isla, caracterizada por una frondosa vegetación perenne y arbórea. Aunque todavía estaba lejos de ser algo generalizado, por el hecho de que la historia de la agricultura cubana "era muy reciente", advertía que se ofrecían muestras diarias de ese fenómeno en la escala de cada nueva comarca entregada al cultivo. La razón era que: «Se talan o queman los bosques; se establecen los plantíos en relación no con las necesidades del país, sino conforme a la demanda comercial; se continúa la explotación mientras que es productiva, y luego se abandonan los terrenos como cansados, buscando otros nuevos, que ponen al descubierto el hacha y el fuego, destructores de la vegetación forestal». ${ }^{3}$

Durante los largos conflictos con los hacendados habaneros en torno a la explotación de los bosques, entre 1772 y 1815, funcionarios de la Marina Real Española llamaron la atención sobre los peligros que conllevaba el rápido auge del cultivo de la caña de azúcar, pues requería dejar amplias porciones del terreno limpio de árboles. Otros observadores como Alejandro de Humboldt, quien visitó la Isla en dos ocasiones en 1800 y 1804, captaron de inmediato la gravedad del desequilibrio entre los cultivos comerciales, en especial el azúcar, y la escasez de cultivos de subsistencia. Su idea de que "la imprudente actividad de los europeos" alteró el orden de la naturaleza, como en otras regiones intertropicales, sintetiza una realidad socioeconómica marcada desde su nacimiento por los intercambios con el exterior de unos pocos artículos con alto valor comercial a cambio de otros artículos de consumo básicos y manufacturas. El sabio alemán se mostraba confiado en que Cuba fuera capaz de cambiar esa relación, «a medida que mejor instruidos los habitantes acerca de sus verdaderos intereses, y desanimados por la baratura de los géneros coloniales», variasen sus cultivos y dieran libre impulso «a todos los ramos de la economía rural». ${ }^{4}$ Pero esto no se cumplió y por el contrario la producción de azúcar de la mayor de las Antillas creció en las décadas siguientes en una proporción que ni el más previsor de los contemporáneos hubiera sido capaz de imaginar.

A menos de un siglo de las advertencias de La Sagra, en 1935, la llamada Comisión de Estudios Cubanos, formada por científicos y humanistas norteamericanos, señalaba como componentes indispensables

3 SAGRA, Ramón de La, Cuba: 1860. Selección de artículos sobre agricultura cubana, La Habana, Comisión Nacional Cubana de la UNESCO, 1963, pp. 22-23.

4 HUMBOLDT, Alejandro de, Ensayo político sobre la Isla de Cuba. Edición y Estudio introductorio Miguel Angel Puig-Samper, Consuelo Naranjo y Armando García, Aranjuez, Madrid, Doce Calles, 1998. 
para la rehabilitación de Cuba la diversificación agrícola, el fomento de la pequeña propiedad y el desarrollo de un programa forestal. Sin embargo, advertían que no era fácil porque: «En la actualidad no hay reglas absolutas para el uso de las tierras, por la razón elemental de que ese uso está afectado necesariamente por las circunstancias y por las condiciones del mercado». ${ }^{5}$ Por entonces no podía hablarse de impactos a escala local como los indicados por La Sagra, sino de la práctica totalidad de la Isla como escenario en distintas épocas de las plantaciones azucareras.

Cuba había llegado al mismo punto que las vecinas islas azucareras del Caribe, las cuales comenzaron a mostrar señales de agotamiento tras perder sus bosques y mantener años de monocultivo; y esto en un plazo mucho más breve si se toma en cuenta la extensión territorial. ${ }^{6} \mathrm{El}$ motivo para esta diferencia fue la escala en que se produjo la conquista de las regiones naturales cubanas por el azúcar, gracias a la expansión por la mayor parte de la isla de las plantaciones azucareras en forma paralela a la introducción de los avances tecnológicos de la revolución industrial.

En estas páginas se mostrará a grandes rasgos la influencia de la agricultura industrial azucarera sobre la transformación de la mayor parte de las regiones naturales cubanas en el periodo de 1815 a 1926 . El constante aumento de la escala de la producción amplificó en una dimensión insospechada las consecuencias adversas en el orden ambiental que ya podían verse en los territorios habaneros en más de dos siglos de crecimiento azucarero y plantacionista. A partir de 1815 y precedida por la transformación ideológica y jurídica en torno a la propiedad y uso de los bosques, los cambios en el aspecto físico de Cuba se sucedieron a un ritmo creciente de acuerdo a la introducción de nuevas y cada vez más potentes tecnologías industriales. ${ }^{7}$ La combinación de

5 Comisión de Estudios Cubanos, Problemas de la Nueva Cuba. Informe de la Comisión de Asuntos Cubanos, New York, Foreing Policy Association, 1935, p. 501.

6 Entre las Islas caribeñas Cuba es la de más extensa, con $110.920 \mathrm{Km}^{2}$. Le siguen La Española (que comparten República Dominicana y Haití), con 76.484 Km², Jamaica, con $11.424 \mathrm{Km}^{2}$ y Puerto Rico, con 8.897 Km², que junto a Islas Caimán $\left(241 \mathrm{Km}^{2}\right)$ componen el grupo de las Antillas mayores, que reúne el $88 \%$ del área terrestre del caribe insular. De ésta Bahamas agrupa el 5\% y las Antillas menores el 3\%. Una obra imprescindible sobre las relaciones de la sociedad, la cultura y el medioambiente en el Caribe insular es la de WATTS, David, Las Indias Occidentales. Modalidades de desarrollo, cultura y cambio ambiental desde 1492, Madrid, Alianza, 1992.

7 Acerca de la incidencia de la historia azucarera de Cuba sobre la transformación del medio natural se pueden consultar a MARRERO, Leví, Cuba, Economía y Sociedad, Madrid, Ed Playor, 1974-1984; FRAGINALS, Manuel Moreno, El Ingenio. Complejo económico social cubano del azúcar, La Habana, Ed. Ciencias Sociales, 1978; BERGAD, Laird, Cuban rural society in the nineteenth century. The social and economic history of monoculture in Matanzas, Princeton, Princeton University Press, 1990. Estudios más específicos sobre el tema son: SMITH, Mark J, "The political Economy of Sugar Production and the Environment of Eastern Cuba, 1898-1923", Environmental History Review, 1995, Vol. 19, núm. 4, pp. 31-48; TUCKER, Richard P., Insatiable Appetite: The United States and the Ecological Degradation of the Tropical World, Berkeley, University of California Press, 2000; y MONZOTE, Reinaldo Funes, De Bosque a sabana. Azúcar, deforestación y medioambiente en Cuba, 1492-1926, México D. F., Siglo XXI Editores, 2004. 
ambos factores en función de la industria productora de azúcar impulsó el gran cambio de aspecto en los paisajes cubanos durante el siglo XIX y primeras décadas del XX, desde un inmenso bosque a una extensa sabana antrópica.

\section{El salto azucarero de fines del XVIII y el cambio ideológico jurídico.}

Mientras el Astillero de La Habana fue uno de los más importantes del imperio español, hubo un freno a la ansiedad de los dueños de ingenio por invadir zonas boscosas debido a la reserva para la explotación forestal en beneficio de las construcciones navales, una de las causas de deforestación hasta fines del siglo XVIII. La irrupción del azúcar en las haciendas ganaderas originales, donde se sacaba la madera para el Astillero habanero, significaba tarde o temprano la aniquilación del bosque, pues con la siembra de los cañaverales y la demanda de leña quedaba sin posibilidades de regeneración a corto o medio plazo. Por este motivo las restricciones sobre la explotación de los bosques habaneros fueron endurecidas desde 1772 y en especial las que hacían referencia a los usos de las mejores maderas en los ingenios de azúcar. Entre estas estuvieron la prohibición de construir las cajas de azúcar con madera de cedro, la exigencia de licencias para cortar determinadas maderas y por último la extensión del control de la Marina Real a todos los bosques de la Isla. Dentro de este proceso se concedió en 1789 al Director de los "Cortes del Rey", el sistema de explotación forestal para abastecer al Astillero de La Habana y los de España, el derecho de veto en las deliberaciones de la Junta de Maderas para conceder las licencias para la demolición de hatos y corrales. ${ }^{8}$

Los enfrentamientos entre construcción naval y agricultura comercial son un importante ejemplo de los cambios que se produjeron en la Isla entre el último tercio del siglo XVIII e inicios del XIX. Hasta esos momentos existía un cierto equilibrio entre la explotación ganadera, la forestal y la agrícola, o al menos no había un claro predominio de alguna por encima de las restantes. Las grandes haciendas de ganado menor y mayor estaban pobladas de abundantes bosques, en parte por no ser muy elevados los requerimientos de pasto y en parte por las características del clima insular y el papel de los bosques dentro de la dieta del ganado durante la estación seca.

8 Las haciendas ganaderas tuvieron su origen en el reparto de las tierras por parte de los Cabildos de la Isla desde el siglo XVI. Se les denominó hatos, cuando se destinaban a la cría de ganado vacuno o mayor y corrales, cuando eran para la cría de cerdos o ganado menor. La extensión ideal de estas haciendas fue fijada en 1.680 caballerías (22.512 hectáreas), en el primer caso y 420 caballerías (5.628 hectáreas) en el segundo. 
El crecimiento azucarero en la zona habanera puso en crisis ese relativo escalonamiento entre ganadería, cortes de madera y agricultura comercial. Hasta el último tercio del siglo XVIII la agricultura comercial se instalaba en los territorios abandonados por los Cortes del Rey, pero fue cada vez más difícil contenerla a esos límites. Por esta razón la Marina buscó hacerse cargo de controlar del proceso de demolición de las haciendas tradicionales, que registraba una notable aceleración con el fin de dejar paso a la agricultura y formas más intensivas de explotación ganadera. Pero los acontecimientos en Haití, el avance del liberalismo económico y la decadencia de las construcciones navales en La Habana pondrían en crisis los añejos privilegios de la Marina sobre los bosques. Los ingenios entraron así definitivamente en las zonas de los Cortes del Rey.

Este proceso estuvo acompañado de una larga discusión sobre el mejor modo de explotación de los recursos forestales. La Marina Real, interesada en preservar sus privilegios, defendía la necesidad de disposiciones superiores para asegurarse el control de los bosques para la construcción naval y en cierta medida para garantizar el abasto de las necesidades públicas de maderas y combustibles. Los dueños de ingenios y hacendados en general sostenían, por el contrario, que el afianzamiento de la propiedad individual sería la mejor garantía para una explotación beneficiosa en el orden económico y para la misma conservación de las masas forestales.

Hasta la última década del siglo XVIII prevalecieron los partidarios de la primera postura, fundamentalmente por consideraciones estratégicas, pero a raíz de la revolución en Haití comenzó a cambiar la balanza. En los últimos intentos por mantener los privilegios para la explotación forestal, los funcionarios de la Marina ofrecieron fundamentos económicos, jurídicos y ecológicos en contra de la entrega los bosques a la exclusiva voluntad de los particulares. Sin embargo, los grandes beneficios del salto azucarero para la oligarquía criolla y la Corona española eclipsaron cualquier razonamiento opuesto al «sagrado" derecho de propiedad. Con argumentos en boga en la metrópoli, como los de la Ley Agraria de Jovellanos, los hacendados habaneros se hicieron eco de los perjuicios de cualquier intervención estatal o limitación sobre la propiedad. Según esta opinión las regulaciones para la explotación de los bosques tenían el efecto contrario al que buscaban. En cierto sentido no era descabellado sostener esas ideas con un argumento que parecía entonces incontrovertible: que los bosques de la Isla eran inagotables y podían durar eternamente.

Los cortes de madera para la construcción naval tampoco podrían considerarse un modelo de conservación de las masas forestales. La preocupación de la Marina tenía que ver más con el distanciamiento de 
los bosques del Astillero de La Habana y los costes adicionales que esto representaba. No obstante, sus funcionarios fueron mucho más previsores de las consecuencias negativas de la deforestación incontrolada por el azúcar. No significa que tuvieran o no la razón. La cuestión es más compleja porque los privilegios de la Marina representaban una monopolio cada vez más repudiado en la misma metrópoli y uno de los símbolos más característicos del antiguo régimen.

Los conflictos entre los dueños de ingenios habaneros y la Marina Real española que comenzaron en la década de 1770 y no terminaron hasta 1815, representan el punto de partida de una gran transformación económica, ideológica y ambiental. Se enfrentaban dos concepciones diferentes de explotación colonial, dos modos de concebir la explotación de los recursos naturales. La de la Marina, más favorable a una economía de subsistencia, al equilibrio entre diferentes producciones y hasta cierto punto de los aprovechamientos comunales de bienes de la naturaleza que en última instancia se estimaban como pertenecientes a la Corona. La de los hacendados, enfocada hacia la producción de mercancías para la exportación y la individualización del uso de los recursos. Finalmente, con el Real Decreto del 30 de agosto de 1815, que concedió a los particulares el derecho absoluto a "abatir" los bosques dentro de sus propiedades, triunfaron los postulados del más exacerbado liberalismo económico de los plantadores cubanos y sus partidarios en la administración colonial.

La libertad para talar los bosques tuvo una trascendencia mucho mayor si se toma en cuenta la distribución de la propiedad de la tierra en la colonia, con un predominio casi absoluto de la particular. A diferencia de España, formas de propiedad territorial como la comunal y los realengos tuvieron una relevancia limitada en Cuba. Se podría decir que mientras en la metrópoli la individualización de buena parte de la propiedad agraria se llevó a efecto en varias oleadas durante el proceso desamortizador del XIX, en el caso cubano tuvo lugar de una sola vez a partir de la entrega de los bosques a la voluntad individual en 1815 y del reconocimiento en 1819 de la propiedad plena sobre las tierras mercedadas por los cabildos desde el siglo XVI hasta 1729, cuando fue prohibida esta práctica por la Corona.

Los propietarios particulares en la colonia defendieron celosamente el derecho a talar sin contemplaciones los bosques obtenido en 1815. Todos los intentos por poner freno a la incontrolada deforestación de la Isla encontraron siempre la oposición decidida de los plantadores (sobre todo de azúcar, pero también café y tabaco), quienes eran conscientes de que el éxito o fracaso de su empresa dependía muchas veces de disponer libremente de los bosques. Los dueños no atendieron por lo general otras consideraciones de orden científico, social o incluso eco- 
nómico acerca de los peligros de la deforestación. Esta mentalidad guió las relaciones del azúcar con el medio hasta que el fin de los bosques de las regiones Ilanas y onduladas de la Isla estuvo prácticamente consumado. ${ }^{9}$

Cuando la metrópoli comenzó a indagar desde 1844 sobre los efectos en Cuba del Real Decreto del 30 de agosto de 1815, la respuesta de la Junta de Fomento desde La Habana fue que "habiendo sido tan felices y satisfactorios, como pudiera medirse por el presente estado de la agricultura, sin ofrecer el menor inconveniente, ni dar lugar a la más leve reclamación, había faltado motivo para que se reuniese la Junta mandada a crear, limitándose a quedar instalada en mayo de 1816". ${ }^{10}$ Dos años después el Superintendente de Hacienda, conde de Villanueva, explicaba los motivos por los que se oponía a nuevos intentos por regular la tala de los bosques:

La demolición o división de las grandes haciendas montuosas, tan recomendada en diversas soberanas resoluciones y tan necesarias para el fomento de la población blanca, quedaría enteramente obstruida; y la imposibilidad de trasladar los ingenios a terrenos vírgenes, vendría decreciendo poco a poco su producción, hasta que por lo cansado del suelo y lo costoso de su conservación fuera preciso destruirlos, cual hoy acontece con casi todos los que cuentan más de cuarenta cosechas. ${ }^{11}$

En 1876 fueron promulgadas las Ordenanzas de Montes (para Cuba y Puerto Rico), después de más de 30 años de indagarse por primera vez sobre los efectos de la libertad para talar los bosques. Las últimas colonias españolas en América no podían permanecer ajenas a la modernización de la actividad forestal en la metrópoli por medio de la creación de una escuela y de un cuerpo específico encargado de la administración de las masas forestales propiedad del Estado y los comunales. Estas ordenanzas representaron un importante cambio de actitud de España respecto a los bosques cubanos, impulsado en parte por el deseo de obtener ingresos para la hacienda. Sin embargo, su trascendencia fue muy limitada. Al no contemplar los montes particulares, el área afectada por estas disposiciones resultaba apenas entre un 5 y un 10\% de la colonia. El resto se mantenía sujeto a la libre voluntad de los dueños y como bien se encargaban de advertir los ingenieros forestales, no se

9 Parafraseando a John McNeill se podría decir que el crecimiento económico o en este caso el crecimiento azucarero, se convirtió en una seductora religión que se puso por encima de cualquier otra previsión en el orden social y ecológico. MCNEILL, John, Something New under the Sun. An Environmental History of the Twentieth Century, Gran Bretaña, Penguin Books, 2001, pp. 325-335.

10 "Corte de Maderas, artículo 7", Anales de la Junta de Fomento, t. 4, 1851, p. 342.

11 AHN, Ultrmar, Fomento, leg. 225, Exp. 10. Da cuenta de un acuerdo tenido en la Junta de Autoridades, proponiendo la reforma del Artículo $2 \square$ de la real Orden de 23 de marzo último..., La Habana, junio 29 de 1846, conde de Villanueva.

112 VARIA HISTORIA, $\mathrm{n}^{\circ} 33$ 
podía contar conque aquellos los conservasen pues sólo les interesaba el beneficio inmediato.

Hubo que esperar a la última gran ofensiva sobre los bosques cubanos a raíz de la primera guerra mundial para que se llegase a plantear como algo imperioso la necesidad de imponer restricciones a la explotación forestal. Finalmente en abril de 1926 se prohibió, por primera vez desde 1815, la tala de bosques de propiedad particular para sembrar caña de azúcar, después de una serie de disposiciones que apuntaban tímidamente en esa dirección. Entre una fecha y otra la producción de azúcar aumentó unas 120 veces, pero al mismo tiempo la cubierta forestal se redujo de más del $80 \%$ del territorio a fines del siglo XVIII a un 15\% o cuando más el $20 \%$, concentrado sobre todo en las zonas montañosas.

Por sí sola la propiedad particular sobre los bosques no hubiera sido capaz de provocar transformación tan grande de los paisajes cubanos en poco más de una centuria, pero sin dudas representó un factor fundamental para el afianzamiento de una agricultura industrial y su creciente potencial de simplificación de los ecosistemas. Sin la posibilidad de disponer libremente de estos recursos, la historia podría haber sido distinta o al menos de una escala diferente. Sin la mecanización de la industria, sin los ferrocarriles y otros modernos medios de comunicación y la ampliación del mercado, entre otros factores propios de la era de la revolución industrial, el derecho a abatir con entera libertad los bosques de propiedad particular no habría tenido tal vez una incidencia tan marcada. Fue la combinación de estos dos elementos lo que determinó que el aspecto de la mayor parte de las regiones naturales llanas o alomadas de Cuba diera un vuelco radical entre 1815 y 1926.

\section{La agroindustria azucarera y los campos cubanos hasta fines del siglo XIX.}

Hasta fines del siglo XVIII la producción azucarera en Cuba tuvo por centro principal la zona habanera, en un radio creciente alrededor del principal puerto y centro urbano de la colonia. Gracias a la acumulación de riquezas favorecida por la condición de puerto escala de la Flota española en su tránsito entre la metrópoli y sus colonias continentales, se inició en sus alrededores la producción de azúcar con fines comerciales al comenzar el siglo XVII. Hasta la década de 1670 se produjo un relativo auge de azucarero, con la fundación de cerca de un centenar de ingenios en las zonas más cercanas al puerto. A partir de entonces, sin embargo, el azúcar entró en una prolongada crisis de la que no saldría de forma definitiva hasta la época de la creación en 1739 de la Real Compañía de Comercio de La Habana. Aunque en todas esas décadas nun- 
ca dejó de ser una alternativa económica importante, se vio relegada en buena medida por la competencia de otras zonas productoras en los mismos mercados de la metrópoli e internamente por la preferencia de muchos hacia el cultivo tabacalero.

Las nuevas condiciones a raíz del proceso de reformas emprendidas por los borbones desde su ascenso al trono del imperio español propiciaron una reanimación del azúcar que a partir de entonces no dejaría de acrecentar su influencia en la economía y sociedad insular. La toma de La Habana en 1762 por los ingleses y su ocupación por once meses hizo que se aceleraran tras su recuperación las reformas administrativas y comerciales en el sistema colonial de España, con ejemplos como el Reglamento y Aranceles para el comercio libre entre España e Indias de 1878.

El número de ingenios en los territorios rurales de La Habana se incrementó de 93 en 1755 a 102 en 1771 y 168 en 1778. Cuando se inicia el gran salto azucarero a raíz de la sublevación de los esclavos en Haití, los ingenios en los partidos habaneros y de la zona de Matanzas, según el censo de 1792, sumaban ya 245. Como efecto de la excepcional coyuntura en 1804 su número llegó a 350 establecidos y otros 50 en fomento en la misma zona. Esto significa que en el transcurso de ocho años aumentó unas cuatro veces el ritmo anual de fundación de fincas azucareras, que también incrementaron su capacidad de producción. Entre 1759 y 1761 los mayores ingenios contaban con cerca de 100 esclavos y producían entre 10.000 y 15.000 arrobas de azúcar. Cuatro décadas más tarde estos eran los indicadores promedio para el total de fincas azucareras, mientras que los mayores ingenios se ubicaban en torno a los 300 esclavos y alrededor de 40.000 arrobas de azúcar anuales.

El crecimiento azucarero de todas estas décadas no tuvo grandes cambios desde el punto de vista técnico, ni siquiera a partir de la aplicación de innovaciones introducidas en las Ilamadas Sugar Islands para el ahorro de combustibles o el perfeccionamiento de los métodos del cultivo. A finales del siglo XVIII resultó fallido el primer intento por aplicar la máquina de vapor a la producción de azúcar, hasta que a partir del año 1818 comenzó a tener el éxito deseado. En el censo de 1827 se contaban 26 máquinas de vapor en los ingenios de La Habana y Matanzas. Dos décadas después la utilizaban 251 ingenios del total de 735 en los mismos territorios. Hacia 1860 el $77 \%$ de las fincas azucareras del Departamento Occidental (829 ingenios) empleaban máquinas de vapor. El uso de éstas en el Departamento Oriental era menor (en el 40\% de las fincas), lo que explica en parte la menor incidencia del azúcar en territorios que además eran mucho más extensos.

El empleo de la fuerza del vapor para la producción de azúcar fue acompañado por la generalización de los llamados trenes jamaiquinos, 
con el objetivo de reducir el enorme consumo de combustible, y dio lugar al denominado Ingenio semimecanizado, de acuerdo a la clasificación de Moreno Fraginals. ${ }^{12}$ Hacia la década del 1840 se inició la sustitución de esos trenes jamaiquinos por los aparatos de triple efecto o evaporación al vacío. Esto permitió una nueva ampliación de las capacidades productivas de las fábricas de azúcar, que en palabras de Moreno condujo al inicio de un nuevo proceso industrial y al nacimiento del ingenio mecanizado. Hacia el año 1860 el peso de la producción recaía en los ingenios semimecanizados, aunque aún existían muchos de fuerza motriz animal. En el caso de los mecanizados la producción por finca era mucho mayor, pero su número era significativamente menor.

A partir de la libertad de talas en 1815 la mayor parte de los ingenios semimecanizados y mecanizados ocuparon nuevas tierras en la frontera Este de la expansión azucarera, buena parte de estas cubiertas de extensos bosques. En esta expansión fue decisiva la llegada del ferrocarril. La Isla se convirtió en uno de los primeros territorios en contar con ese medio de transporte, séptimo en el mundo, segundo en América y diez años antes que en su metrópoli. Los ferrocarriles facilitaron el traslado del producto final hacia los puertos de embarque y la apertura de zonas menos accesibles, elemento decisivo para el aumento de la producción en quince veces entre 1815 y $1875 .{ }^{13}$

Los principales escenarios de este crecimiento fueron los territorios de las actuales provincias de Matanzas y Santa Clara y Cienfuegos, representativos de la gran plantación esclavista azucarera, los cuales sufrieron el mayor ritmo de deterioro ambiental durante el siglo XIX. No quiere decir que en la mitad Este de Cuba y la porción occidental, no ocupados por las grandes plantaciones, estuvieran ajenas del todo a la producción de azúcar; pero su potencial de transformación del medio fue entonces mucho menor. Los patrones de ocupación territorial se mantuvieron básicamente dentro del sistema de tumba y quema de bosques para ocupar tierras "vírgenes", con el objetivo de reemplazar las ya desgastadas y suplir las necesidades de combustible. Sólo con la aparición de las mayores fábricas de la fase del ingenio mecanizado, se inició la tendencia al abandono del carácter portátil de los ingenios azucareros. La Guerra de los Diez Años (entre 1868 y 1878) contribuyó en ese sentido, al frenar momentáneamente la continuación de la marcha expansiva de la industria hacia el Este.

El impacto de la mecanización de la producción de azúcar sobre el medio natural motivó serios temores entre científicos y algunos hacenda-

12 FRAGINALS, Manuel Moreno, El Ingenio. Complejo económico social cubano del azúcar, t. 1, p. 169-171.

13 Para profundizar en la historia azucarera de Cuba se pueden consultar: ZANETTI, Oscar y GARCÍA, Alejandro, Caminos para el azúcar, La Habana, Ed. Ciencias Sociales, 1987 y MOYANO, Eduardo L., La nueva frontera del azúcar: El ferrocarril y la economía cubana del siglo XIX, Madrid, CSIC, 1991. 
dos previsores por las implicaciones medioambientales del crecimiento azucarero. Parte de la solución consistió en importar carbón de piedra para frenar la rápida desaparición de los boques, como lo pedía una instancia del hacendado Francisco Diago en 1847, al plantear que de su conservación dependía el porvenir, "muy cercano en verdad", de "todas las industrias de la Isla, agrícolas y fabriles, y muy particularmente las que tienen por objeto las construcciones urbanas, la arquitectura naval y los caminos de hierro". ${ }^{14}$ A pesar advertencias como esa, el empleo de combustible de origen orgánico para las maquinarias de la era del vapor fue común en la industria azucarera y los ferrocarriles cubanos hasta las dos primeras décadas del siglo XX, a la par que se incrementaba la utilización de los fósiles.

A la vez que la complejidad tecnológica imponía el fin del carácter portátil de la industria, se daban los primeros intentos para mejorar el cultivo cañero por medio de la aplicación de la ciencia agronómica. Evidencias de la preocupación por las consecuencias ambientales de la acelerada desaparición de la cubierta boscosa de Cuba y el agotamiento de la fertilidad de sus suelos se pueden encontrar en varios autores a lo largo del siglo XIX. Un buen ejemplo fue la obra del conde de Pozos Dulces a favor de la reforma del sistema de cultivo, por medio de la pequeña propiedad y la aplicación de abonos. Su prédica se dirigió a la sustitución del cultivo extensivo y migratorio, que esquilmaba y esterilizaba a su paso, por una agricultura previsora y libre de eventualidades. Según decía, cada nuevo camino de hierro que se emprendía era una revelación de la necesidad de «correr en pos de los tesoros que ya se agotaron en el espacio recorrido». Como evidencia ponía que los mejores ingenios y vegas estuvieron situadas cerca de la capital, mientras que para encontrarlas entonces era preciso «recorrer dilatados espacios (...) hacia la Vuelta arriba o la Vuelta Abajo, cuya separación, por comarcas hoy completamente estériles y esquilmadas, es la mejor refutación del sistema que pretende poder pasarse sin abonos». 15

Preocupaciones similares fueron señaladas por su hermano José Jacinto de Frías y Jacott, al referirse en 1851 a los llamados «Ingenios monstruos", como los que se fundaban en la zona matancera de Banagüises. ${ }^{16}$ El término identificaba a las unidades capaces de producir en una zafra igual cantidad de azúcar que la suma de otros tres ingenios

14 AHN, Ultramar, Leg. 23, exp. 4, Instancia a la Junta de Fomento de Francisco Diago solicitando la libre importación de carbón de piedra, 1848.

15 FRÍAS, Francisco de y Jacott (Conde de Pozos Dulces), Colección de escritos sobre agricultura, industria, ciencias y otros ramos de interés para la Isla de Cuba, París, Imp. De Jorge Kugelmann, 1860.

16 Sobre la ocupación de la zona de Banaguises por el azúcar consultar BERGAD, Laird, Cuban Rural Society in the Nineteenth Century. The Social and Economic History of Monoculture in Matanzas, pp. 116-140. 
buenos. A pesar de sus ventajas en la economía de brazos y sueldos y los cuidados en la elaboración, veía un gran inconveniente en la extensión necesaria para «mantener el plantío suficiente al gran producto que se busca y que se espera, dando por invariable - según advertía - el sistema de sembrar en tierras nuevas y abandonar los cañaverales cansados, y contando con la ausencia total de todo procedimiento para perfeccionar el cultivo y mejorar los terrenos». Se preguntaba cuál sería el destino de esas colosales construcciones, costosos trenes y soberbias máquinas de vapor, grandes barracones y ferrocarriles para conducir la caña y los azúcares, cuando el terreno se empobreciera y en vez de 10 mil cajas sólo se obtuvieran 5 mil: «¿Qué se hará con ese dilatado espacio de terreno, que si bien ha producido montones de oro, ha quedado estéril, sin bosques, y en los que descollarían como antiguas ruinas los restos de las costosas fábricas». ${ }^{17}$

La reanudación del movimiento expansivo hacia el Este después de la Guerra de los Diez Años coincidió con el inicio de la transición del ingenio semimecanizado y mecanizado al moderno central azucarero dentro del proceso de concentración de la producción en fábricas cada vez más grandes junto a la descentralización de la oferta de caña a partir del denominado sistema del colonato. La mitad oriental de la Isla contaba todavía con extensos bosques, lo que continuaba siendo una irresistible atracción para el negocio azucarero. Aunque su empleo como combustible y maderas de construcción no era imperioso como en épocas anteriores, permanecía la preferencia por las tierras boscosas para obtener mayores rendimientos cañeros. Por otra parte, los precios de esas tierras eran los más bajos, además de que las maderas contribuían a amortizar la inversión inicial por sus diferentes usos y su venta en el mercado en caso de ser necesario.

A diferencia de épocas anteriores en que un solo propietario dominaba los sectores agrícola y fabril de la agroindustria azucarera, se impuso la tendencia a la separación de ambas fases con la conversión de numerosas fincas en abastecedoras de caña a las unidades que dieron el salto tecnológico o a las nuevas fábricas que comenzaron a establecerse en zonas no ocupadas previamente. De esta forma, el área dominada por el núcleo industrial de la producción de azúcar fue mucho mayor. A la vez que decrecía la cantidad de fincas azucareras, la producción total de Cuba fue en aumento hasta rebasar por primera vez en 1894 el millón de toneladas de azúcar. La historiadora Fe Iglesias distingue dos fases del proceso de concentración entre 1880 y 1894 y destaca la nue-

17 FRÍAS Y JACOTT, José J., «Ingenios de fabricar azúcar. Beneficios productivos que deja el capital invertido en estas fincas. Ventajas y desventajas de los ingenios Monstruos", Memorias de la Sociedad Económica de Amigos del País, 1851, t. 42, pp. 53-62. 
va guerra de independencia entre 1895 y 1898 como un momento decisivo, que aceleró la transición del ingenio al central. ${ }^{18}$

En la fase de concentración azucarera el ferrocarril volvió a ser un factor decisivo, pero en este caso no sólo para transportar el producto final sino también para abastecer la creciente necesidad de materias primas de las fábricas. Con este auxilio el potencial de transformación de los paisajes se multiplicó considerablemente. En 1890 se escribía desde las páginas de la Revista de Agricultura: "Ios ferrocarriles fueron alargando sus tentáculos de acero en busca de nuevas y feraces colonias y un día dos ingenios que algunos años antes se veían separados por espesísimos bosques, se encuentran al extremo de sus líneas luchando por tal o cual zona de reconocido valor para el cultivo". ${ }^{19}$

Los propietarios de los modernos ingenios-centrales en las antiguas zonas de la plantación esclavista desde la zona habanera hasta el centro de la Isla, tuvieron que preocuparse necesariamente por la transformación del sistema de cultivo. Esta previsión, sin embargo, no fue necesaria en el caso de los ingenios centrales que comenzaron a aparecer en las regiones naturales de la mitad oriental de la Isla. En realidad varios de los proyectos más divulgados en la época insistieron en mostrar las enormes posibilidades de ubicarlos en zonas cubiertas de bosques. ${ }^{20}$ En algunos casos incluso se vio este desplazamiento como un medio para evitar la incidencia del sistema del colonato en los territorios de la mitad occidental, debido a la reorientación de muchos pequeños agricultores al antes vedado cultivo de la caña de azúcar. El agrónomo Nicomedes P. de Adam exponía en 1888:

Cese la obra de destrucción (...) Continúese en buena hora, si se quiere, en las selvas vírgenes de nuestras provincias del Centro y Oriente, donde se fomentan soberbios centrales, que serán los únicos ingenios que dentro de algunos años podrán soportar la competencia extranjera (...) ¡Pero que no caiga ni una mata de plátanos más, ni una palma, ni un cafeto, por virtud de la mano que debiera protegerlos! ${ }^{21}$

El hecho de que la presencia de los primeros ingenios centrales de la zona centro oriental de Cuba se diera de forma aislada, con núcleos más localizados como la zona de Yaguajay o las Ilanuras de Manzanillo y de Guantánamo, hace que no pueda hablarse todavía en la etapa de

\footnotetext{
18 GARCíA, Fe Iglesias, Del Ingenio al Central, La Habana, Ed de Ciencias Sociales, 1999.

19 GARCÍA, José de la O., "Centrales y colonias", Revista de Agricultura, núm. 7, febrero 16 de 1890, p. 77.

20 IBAÑEZ, Francisco Feliciano, Observaciones sobre la utilidad y conveniencia del establecimiento en esta Isla de grandes Ingenios centrales para salvar nuestra agricultura e industria azucarera por el aumento de la producción y disminución de gastos..., La Habana, Imp y Litografía Obispo, 1880; y Proyecto para la creación por el Gobierno de la nación, de cincuenta centrales con empleo exclusivo de trabajadores libres..., La Habana, Litografía El Sol, 1881.

21 ADAN, Nicomedes P. de, "Cultivos menores", en Revista de Agricultura, septiembre de 1883, p. 242.
} 
1880 a 1898 de un paisaje dominado por las plantaciones cañeras. Al cese de la soberanía española contenían sus territorios la mayor parte de los bosques existentes en la Isla, que se estimaban entre el 40 y el 50 $\%$ del total de su superficie. Además de las extensas zonas dedicadas a la ganadería extensiva tradicional, entremezcladas con zonas boscosas, existía una importante actividad maderera en varios puntos, y haciendas relativamente extensas dedicadas al cultivo del plátano o de cocoteros. Pero en menos de dos décadas la mitad Este de Cuba se convertiría en el escenario por excelencia del salto azucarero más dramático en la historia del país, que desparramó en sus territorios los antes casi inexistentes ferrocarriles públicos y privados, los centrales azucareros más grandes del mundo y los cañaverales más extensos conocidos hasta entonces.

\section{La llegada definitiva del paisaje agroindustrial al Este de Cuba, 1898-1926.}

Los cambios políticos a partir de 1898 con la intervención de los Estados Unidos en la guerra que libraban los independentistas cubanos contra España y su ocupación de la Isla durante casi cuatro años, sentaron la base para la transformación de los paisajes de Cuba a un ritmo vertiginoso. Una afluencia masiva de capitales norteamericanos arribó al país para dominar paulatinamente el negocio azucarero, en correspondencia con el status económico y político de la República inaugurada el 20 de mayo de 1902. La principal garantía para esos intereses sería la protección que representaba la denominada Enmienda Platt, introducida bajo presión de los ocupantes a la Constitución elaborada en 1901, por la cual se confería a los EE. UU. el derecho a intervenir en la Isla para "el sostenimiento de un Gobierno adecuado, a la protección de la vida, la propiedad y la libertad individual".

En 1903 se le uniría en el plano económico la firma de un Tratado de Reciprocidad comercial por el que se reducían en un 20 por ciento los derechos para el azúcar y otros artículos cubanos para su entrada al mercado estadounidense, a la vez que la nación vecina recibiría en compensación rebajas arancelarias de entre un 25 y un 40 por ciento para varios de sus productos. Se afianzaba así la dependencia de la producción y el consumo de Cuba hacia un mismo mercado. ${ }^{22}$

La recuperación de la producción de azúcar en Cuba se inició tras la terminación de la guerra y su crecimiento se mantuvo de forma ininterrumpida durante un cuarto de siglo. Se pueden diferenciar dos etapas delimitadas por el estallido de la primera guerra mundial y su incidencia

2 ZANETTI, Oscar, Los cautivos de la reciprocidad, La Habana, Ciencias Sociales, 2003.

Janeiro, 2005119 
en la producción del azúcar cubano y en la inversión de capitales norteamericanos en el sector. Entre 1898 y 1914 creció hasta 2.244.500 Tm ese último año, para aumentar hasta 4.104.100 Tm en 1919 y 5.200.800 en 1925. Como consecuencia directa de la caída de la producción de azúcar de remolacha en Europa, la exportación cubana dentro del total mundial subió del 16 al 24\%. El cenit de este salto azucarero, de mediados de 1918 a mediados de 1920, ha pasado a la historia como «la danza de los millones» o «las vacas gordas». De 1915 a 1919 se inauguraron 34 centrales y de 1920 a 1926 otros 16, para un total de 50, el doble de los construidos entre 1900 y 1915. Gracias a esto afirmaba en 1920 un artículo publicado en The National Geographic Magazine que Cuba era «El Dorado» del mundo y el azúcar su Rey, con la que se podían construir dos pirámides como la de Cheops. ${ }^{23}$

Los altos precios durante la guerra y los años inmediatos de la posguerra atrajeron como nunca antes la atención del capital financiero de procedencia norteamericana. Se estima que hasta 1915 sus inversiones en el azúcar llegaban a unos 50 millones de dólares, cifra que se incrementó hasta en un 1,200\% en sólo seis años. ${ }^{24}$ César Ayala resalta que en 1924 el área del Caribe y en especial Cuba eran las de mayor concentración de las inversiones de Estados Unidos en todo el planeta en cuanto a extensión territorial y población, representando un 63\% del total correspondiente a negocios agrícolas. ${ }^{25}$ Este gran aporte de capitales se dirigió tanto a la erección de nuevas y cada vez más potentes fábricas como a la ampliación de la capacidad de otras ya instaladas, así como a la adquisición de extensos territorios y la multiplicación de los ferrocarriles privados para garantizar la caña requerida. ${ }^{26}$ Estos cambios aceleraron la formación de grandes latifundios, mayormente de propiedad norteamericana, cuyas consecuencias económicas y sociales fueron expuestas desde entonces por autores como Ramiro Guerra en su Azúcar y población en las Antillas. ${ }^{27}$

Los grandes centrales y latifundios azucareros se establecieron por lo general en las provincias de Oriente y Camagüey, que como se dijo contaban todavía con extensos bosques al iniciarse el siglo XX a diferen-

23 SHOWALTER, William J., "Cuba. The sugar mills of the Antilles», en The National Geographic Magazine, vol. 38, Julio, 1920, p. 24.

24 SANTOS, Oscar Pino, El asalto a Cuba por la oligarquía financiera yanqui, La Habana, Ed Ciencias Sociales, 1977. Detalles al respecto se pueden encontrar en SANTAMARíA, Antonio, Sin azúcar no hay país, La industria azucarera y la economía cubana (1919-1939), Sevilla, CISC, E.E.H.A, Universidad de Sevilla, 2001, pp. 46-47.

25 AYALA, César, American Sugar Kingdom: the plantation economy of the Spanish Caribbean, 1898-1934, The University of North Carolina Press, 1999, pp. 77-78.

26 Ver DYE, Allan, Cuban Sugar in the Age of Mass Production: Technology and the Economics of Cuban Sugar Central, New York, Stanford University Press, 1998 y Antonio Santamaría, Sin azúcar no hay país. La industria azucarera y la economía cubana (1919-1939).

27 GUERRA, Ramiro, Azúcar y Población en las Antillas, La Habana, Ed. Minerva, 1927. 
cia de las regiones azucareras tradicionales. Hasta los inicios del proceso de concentración en las últimas décadas del siglo XIX las fincas productoras de azúcar se fundaban a partir de la subdivisión de los antiguos hatos y corrales ganaderos, como parte de cierta diversificación de la explotación económica de las tierras. Pero los centrales construidos a partir de 1898 podían dominar por sí solos el área de una o varias de aquellas haciendas originales. Tierras que antes aparecían formadas por bosques, sabanas de pasto y áreas de cultivo o subdivididas en ingenios, potreros, estancias y otras fincas rurales, se destinaban ahora casi exclusivamente a cañaverales o potreros. Nunca la simplificación de los ecosistemas había llegado a tal grado.

En 1925 las provincias Camagüey, Oriente y Santa Clara producían cada una tanto como la zafra más grande de toda la Isla en la anterior centuria. Este salto azucarero se debió en gran medida a la aparición de los llamados «ingenios colosos», por el total de azúcar que eran capaces de producir en un día o en una zafra. En un estudio de la década de 1940 se incluían dentro de esa categoría un total de 27 centrales, construidos todos durante el primer cuarto de siglo en Camagüey (15) y en Oriente (12). ${ }^{28}$ Con el objetivo de satisfacer la capacidad de molienda de estas fábricas se conformaron gigantescos latifundios, con redes ferroviarias privadas que hacían posible la llegada de la caña dentro del límite de tiempo requerido. En ambas provincias la extensión de los ferrocarriles privados superaba el total de líneas existentes en toda Cuba antes de 1898, mientras que la producción de más de un millón de Tm de azúcar en tan sólo 15 o 12 unidades igualaba lo logrado a fines del XIX por unas 400 fábricas. La cantidad de tierras controladas por estos colosos, por poner otro ejemplo, sobrepasaba ampliamente la de los 1,365 ingenios de la isla en 1860 (59,425 caballerías en total).

Esas gigantescas fábricas de azúcar dominando miles de caballerías de tierras representan el triunfo definitivo de una agricultura industrial sobre las regiones naturales llanas y alomadas. Las modernas tecnologías lograron triplicar los rendimientos en la elaboración de azúcar y redujeron notablemente los costes de producción. Esto no hubiera sido posible sin los factores políticos y económicos indicados antes que crearon, como explican Dye y Santamaría, un «marco institucional» adecuado para atraer las grandes inversiones de capital norteamericano hacia el negocio azucarero y liberar su potencialidad productiva. El hecho de que el flujo inversionista se dirigiera con preferencia a Camagüey y Oriente es explicado por los incentivos económicos de la región, donde era más fácil acceder a

28 El término de «ingenios colosos» es empleado por ABAD, L. V de, Azúcar y caña de azúcar. Ensayo de orientación cubana, La Habana, Ed. Mercantil Cubana, 1945, Capitulo XVIII, pp. 391-428. 
la propiedad sobre grandes extensiones de tierra, establecer redes ferroviarias propias y ejercer mayor control sobre los cultivadores. ${ }^{29}$

En verdad no se podría decir que esos colosos azucareros fueran un gran éxito económico, pero sus repercusiones más negativas aparecieron en el orden social, político y ambiental. Al aumentar la escala de la producción se agravaron en proporción similar muchos de los viejos problemas generados por el avance del azúcar por los campos de Cuba. Por ejemplo, respecto al tiempo de molienda de los citados 27 grandes colosos Luis V. de Abad concluía: «De modo que esas grandes plantas y esa red de ferrocarriles que cruzó sobre una extensión de tierras, en conjunto, más grande que la isla de Puerto Rico sólo prestan servicios en una ¡Sexta parte del año!». ${ }^{30}$ Junto al llamado «tiempo muerto» se puede mencionar la agudización de la tradicional escasez de alimentos de subsistencia, paralela a la destrucción de la pequeña y mediana propiedad o bien a su dedicación exclusiva al cultivo de la caña. Como indicaba Ramiro Guerra el latifundismo redujo a Cuba a un «inmenso campo de producción de azúcar a bajo precio».31

El ingenio mecanizado y más tarde el ingenio-central fueron la culminación del proceso de subordinación de regiones cada vez más extensas a los requerimientos de las tecnologías industriales. Por mencionar sólo uno de los indicadores del gigantesco salto, basta señalar que las primeras máquinas de vapor instaladas a los ingenios de la Isla en la segunda y tercera década del siglo XIX producían de 8 a 12 caballos de fuerza. Un siglo más tarde la mayor fábrica azucarera del mundo, el central Jaronú, reunía en sus aparatos una potencia de 14,124 caballos de fuerza. Con el incremento de la capacidad productiva aumentó proporcionalmente el área de cañaverales controlada por cada central. La producción promedio de los 186 ingenios centrales existentes en 1907 fue de 7,949 Tm en 131 caballerías de caña; en 1913 de 14,249 Tm en 176 fábricas y 267 caballerías cosechadas; y en 1919 llegó en 192 fábricas a una media de 19,455 Tm y cañaverales con una extensión de 346.7 caballerías. ${ }^{32}$

El rápido crecimiento de la agroindustria azucarera durante la primera guerra mundial significó el fin de la ocupación de las regiones natura-

29 Ver obras citadas de Allan Dye y Antonio Santamaría. En 1904 se vendía la caballería en Camagüey y Oriente de 100 a 800 pesos, pero si se compraban grandes lotes los precios descendían a menos de 100 pesos, mientras que en otras provincias no bajaba de 300 y 400 pesos. Tomados de La República de Cuba. Breve reseña para la Exposición Universal de St. Louis, p. 34-37. En la provincia de La Habana se estimaban entre 400 y 2,000 pesos. En Matanzas y Santa Clara variaban entre 300 y 800.

30 ABAD, Luis V. De, Azúcar y caña de azúcar, p. 406. Afirmaba de esos colosos que en general fueron un fracaso financiero y que en los últimos veinte años rara vez habían dejado utilidades.

31 GUERRA, Ramiro, Azúcar y población en las Antillas, pp. 87-92. El fomento en gran escala del monocultivo azucarero para la exportación convertía a la comunidad «en una mera dependencia, en un simple satélite, en un taller de trabajo, al servicio de una metrópoli económica exterior»

32 Para 1907: Censo de la República de Cuba. Bajo la administración provisional de los Estados Unidos, 1907, 
les cubanas propicias para el cultivo de la caña de azúcar. La crisis de sobreproducción al cambiar el mercado azucarero después de la guerra y la abrupta caída de los precios a inicios de la década de 1920 produjo la primera gran alarma sobre las consecuencias económicas y sociales de la enorme extensión del latifundio azucarero. Las zafras crecieron hasta alrededor de un millón de Tm más en los años siguientes por la puesta en producción de nuevas fábricas, pero después de 1925 se inició una política de regulación de la industria y limitación de la oferta. En 1926 la denominada Ley Verdeja prohibía el fomento de nuevos centrales y fijaba en 4.500.500 Tm el tope de producción. ${ }^{33}$

Coincidentemente, ese mismo año, por medio del Decreto núm. 495, firmado por el Presidente Gerardo Machado el 13 de abril, se dictó la "Prohibición absoluta de hacer talas en los montes altos del Estado o de particulares". Esta disposición impedía por primera vez desde 1815, al menos formalmente, la libertad de talar bosques para la siembra de cañaverales y fue prorrogada año tras año hasta la década de 1930, cuando se convirtió en Ley. Desde luego, era tarde para evitar los enormes desmontes que se hicieron durante la guerra o después de ella para siembras de caña que no pocas veces fueron después un fracaso. De esta situación daba cuenta años más tarde el informe Problemas de la Nueva Cuba, donde se concluía sobre los efectos del período de alza que siguió a la primera guerra mundial: "se perdieron millones de pesos en la inútil extensión de siembras de caña». Poco después se añadía, "se conoce de ejemplos en que un gran central se construyó solo para encontrar después que las tierras locales no eran adecuadas para la caña". ${ }^{44}$

En el primero de los Por cuanto del Decreto del 13 de abril de 1926 se exponía que «las talas en superficies extensivas del territorio cubano» habían creado un estado de opinión favorable a la defensa de los bosques y la repoblación forestal, tanto por su beneficiosa influencia física y en la salubridad del país como por no continuar siendo «tributarios del extranjero» de maderas que la Isla era capaz de proporcionar. El segundo refería la doctrina de que cada nación debía conservar un área forestal no menor de la tercera parte de su superficie total y exponía al respecto:

Washington, Oficina del Censo de los Estados Unidos, 1908; para 1913: Secretaría de Agricultura, Comercio y Trabajo, Portfolio azucarero. Industria azucarera de Cuba, 1912-1914; y para 1919: Censo de la República de Cuba, año de 1919, La Habana, Maza, Arroyo y Caso Impresores, 1919.

33 SANTAMARÍA, Antonio, Sin azúcar no hay país. La industria azucarera y la economía cubana (1919-1939), pp 157-203.

34 Comisión de Asuntos Cubanos, Problemas de la Nueva Cuba, New York, Foreing Policy Asociation, 1935, pp. 501-519. 
...siendo así que en la actualidad los montes de Cuba no cubren ni el diez por ciento de su territorio, pues el período de alto precio del azúcar y las siembras de caña que se han venido haciendo desde 1922 a la fecha, amenazan concluir con los escasos montes que aún nos quedan, exigiendo que el Estado ejerza intervención en los predios forestales de propiedad particular, imponiéndoles, en bien del interés público, justificadas limitaciones. ${ }^{35}$

Otro motivo para esta medida era que «en los bosques que se talan (...) sólo se aprovecha alguna madera dura para traviesa y algunos gruesos troncos para tablas, pues todos los demás productos del monte se destruyen por el fuego». De este modo se perdía toda la riqueza forestal «por la nefasta costumbre de quemar los montes por miles de caballerías sin beneficio para sus dueños y con grave daño para la nación, que por su doble error de destruir una riqueza actual para fomentar cultivos, camina hacia dificultades económicas, si no se le ponen coto a dichas talas». Se advertía que las disposiciones vigentes no habían resuelto definitivamente la cuestión, aunque sí pusieron freno a la codicia «excitada por los altos precios que durante la guerra europea alcanzaron los productos forestales». Asimismo se admitió que no era fácil «transformar bruscamente los hábitos de un país pasando de una completa libertad a una rigurosa restricción».

De esa forma se ponía fin a uno de los dogmas más celosamente defendidos por los intereses económicos en la Isla desde la victoria de los hacendados sobre los argumentos de la Marina Real Española en relación con la explotación forestal: el derecho de los particulares a talar libremente los bosques dentro de sus propiedades. No quiere decir que después de 1926 no se produjeran nuevos desmontes para las siembras de caña, pero se puede afirmar que a partir de entonces la elevación de los rendimientos cañeros dependió de otros factores, como el empleo del riego, mecanización agrícola, abonos, agroquímicos y otros componentes de la llamada revolución verde.

La proporción de tierras ocupadas efectivamente por cañaverales en diferentes momentos de la historia azucarera de Cuba seguramente parecerá reducida como para la radical transformación del espacio en poco más de una centuria, aun si se toma en cuenta sólo los territorios Ilanos o alomados ( $75 \%$ de la Isla) o la superficie agrícola dentro del total de tierra firme (estimada en un 62.7\%). Incluso con los datos de las primeras décadas del siglo XX, pudiera parecer que la producción de azúcar no ocupaba una cantidad de tierras suficiente como para ser la primera causa del fin de los bosques cubanos. En 1919, el área de cañave-

35 ALEMÁN, José Isaac del Corral, Derecho Forestal Cubano. Disposiciones fundamentales, La Habana, Imprenta P Fernández y Cía, 1936, Tomo I, 173-175.

124 VARIA HISTORIA, $\mathrm{n} \times 33$ 
rales representaba el $8 \%$ de la superficie total de la Isla, aunque el área ocupada por los latifundios era mucho mayor. Pero si lo observamos a través del tiempo la perspectiva sería muy diferente.

Los poderosos intereses plantacionistas podían darse el lujo de comprar las grandes extensiones de "tierras vírgenes" dentro de las haciendas ganaderas tradicionales, buena parte cubiertas de bosques, para destinarlas a la agricultura. Y como éstas abundaban era más «rentable» dejar a sus espaldas otro tanto de tierras esquilmadas, en ocasiones convertidas en potreros o a disposición de los cultivos menores, cuyo ritmo de ocupación territorial resultaba insignificante en comparación con el de los cultivos comerciales. El azúcar fue sin dudas, directa e indirectamente, el factor más potente de sabanización del territorio cubano.

\section{Algunas implicaciones ambientales de la conquista de Cuba por el azúcar.}

En las diferentes etapas del crecimiento azucarero cubano se alzaron voces de alerta ante las implicaciones económicas, sociales, políticas y medioambientales que podría traer la deforestación sin precedentes gracias a la combinación del derecho absoluto de talar los bosques por los particulares y los avances tecnológicos industriales. Incluso se puede decir que existían los medios y las alternativas para proceder de un modo diferente con relación al cultivo de la caña de azúcar. A pesar de esto, los intereses económicos hicieron caso omiso a las previsiones más autorizadas como ocurrió con el denominado sistema Reynoso, cuyo objetivo era superar el tradicional sistema de tumba y quema para la siembra de la caña de azúcar. ${ }^{36}$

Esa mentalidad fue en gran medida la responsable del deterioro de las condiciones de fertilidad y el agotamiento de los suelos. Las evidencias tras culminar la ocupación de las regiones naturales para la producción de azúcar confirmaron con creces los temores de La Sagra sobre si serían o no indiferentes las grandes talas para abrir paso a la agricultura comercial. Por un lado, este proceso no se limitó a los suelos más adecuados para el cultivo, pues muchas veces la existencia de árboles se consideraba sinónimo de tierras fértiles. Por otro lado, resulta evidente que en varios momentos fue una práctica deliberada para ampliar los campos de caña con vista a aprovechar una buena coyuntura del mercado. ${ }^{37}$

Los graves problemas del deterioro del suelo que afronta hoy Cuba

36 REYNOSO, Alvaro, Ensayo sobre el cultivo de la caña de azúcar, La Habana, Imprenta El Tiempo, 1862.

37 Los otrora rendimientos de más de 150.000 arrobas de caña por caballería y los cañaverales de 20, 30 o 40 años de duración serían hoy una quimera irrealizable. En el Anuario Estadístico de Cuba del 2000 se indica para el sector estatal un rendimiento cañero de $32.2 \mathrm{Tm} / \mathrm{ha}$ y para el sector no estatal $35.9 \mathrm{Tm} / \mathrm{ha}$. 
tienen en parte su origen en las características de la expansión azucarera, que a su paso invadió extensas áreas que nunca debieron ser desmontadas. En la actualidad se estima que dentro de las tierras cultivables sólo el 5.4\% se puede considerar como muy productivas y el $17.8 \%$ como productivas, mientras que $30.8 \%$ se clasifican como poco productivas y $46.8 \%$ como muy poco productivas. Donde se manifiesta mejor la diferencia con los antiguos terrenos en tumbas es en el caso del 69.6\% con muy bajo contenido de materia orgánica y el $44.8 \%$ del total con baja fertilidad. ${ }^{38}$

Al igual que el desgaste de los suelos, otras consecuencias ambientales de la desaparición de los bosques activaron las alarmas desde temprano. Es discutible que la deforestación ocasionara directamente la disminución de las precipitaciones, pero si pudo contribuir a la reducción de sus efectos beneficiosos y a acentuar los perjudiciales. Las referencias a sequías e inundaciones, la disminución del caudal de agua en algunos ríos y torrentes en época de lluvia son frecuentes en obras del siglo XIX.

La deforestación tuvo una incidencia mucho más directa en la desaparición de numerosas especies vegetales y animales. En sus estudios, los naturalistas han comparado el archipiélago cubano con un largo y estrecho almacén floral, que presenta la mayor diversidad florística de las Antillas, con un 51,4\% de endemismo, aspecto en el que sólo le superan la región del Cabo, en Africa del Sur, Hawai y algunas zonas de Australia. De las más de 6.700 especies de plantas vasculares en Cuba, se estima que no menos de 500 especies poseen algún valor económico, alimenticio, medicinal o textil. ${ }^{39}$ Sin embargo, sólo unas pocas decenas de representantes de la flora autóctona se han empleado con esos fines, como productos forestales, medicinales o forraje. Esas posibilidades se han visto considerablemente disminuidas o perdidas, como se puede ver en un estudio preliminar para la elaboración de un Libro Rojo de la Flora del país. ${ }^{40}$

Los representantes de la fauna del archipiélago cubano también han sufrido intensamente los efectos de la deforestación. Muchas de las especies de la fauna cubana tuvieron en su origen una distribución más amplia y algunos de sus ejemplares desaparecieron para siempre. ${ }^{41} \mathrm{Ya}$

38 La degradación de los suelos se considera hoy como uno de los más graves problemas ambientales del país. Ver por ejemplo, Teresita González Novo e Ignacio García Díaz, Cuba, su medio ambiente después de medio milenio, La Habana, Editorial Científico-Técnica, 1998, pp. 73-74. Exponen que el 76.8\% de los suelos presentan problemas de erosión y que el 65\% presenta limitaciones naturales que exigen manejos agrotécnicos especiales.

39 CUEVAS, Jorge Ramón, “La flora de la Mayor de las Antillas”, en Flora y Fauna, La Habana, noviembre, 1996, pp. 1921. También se destaca la flora cubana por su alta densidad de especies por $\mathrm{Km}^{2}, 6$ veces mayor que en California, 7 veces mayor que en España, 36 veces mayor que en la India y China, y 45 veces más que en Australia.

40 BORHIDI, Attila y MUÑIZ, O., Catálogo de plantas cubanas amenazadas o extinguidas, La Habana, Ed. Academia, 1983.

41 Academia de Ciencias de Cuba, Nuevo Atlas Nacional de Cuba, 1989. XI. 
a inicios del siglo XX se daba por extinguido el Guacamayo cubano, la más vistosa de las aves autóctonas. ${ }^{42}$ En la primera mitad del siglo XX también se daban por extinguidas o se consideraban sumamente raras aves como el carpintero real y la paloma viajera. ${ }^{43}$ Otras aves que estuvieron distribuidas por varias regiones se encuentran hoy en hábitats muy restringidos, como la gallinuela de Santo Tomas, que sólo se localiza en la ciénaga de Zapata. En la misma situación dentro de los mamíferos se hallan las diferentes especies de jutías, que constituían parte importante de la dieta de las poblaciones aborígenes, o el Almiquí, un gigante dentro del grupo de los insectívoros que habitó en tiempos precolombinos todo el territorio cubano y se limita hoy a algunas montañas del occidente.

Por supuesto, la desaparición de la fauna no sólo se ha debido a la expansión azucarera. También influyó la caza incontrolada, la exportación de maderas preciosas y otros muchos factores. Pero ningún otro cultivo o actividad económica, incluyendo la ganadería, podría rivalizar con los cañaverales en cuanto a la simplificación de los ecosistemas. No por casualidad se señala que Cuba ocupa el cuarto lugar entre los países del Nuevo Mundo que más han sufrido la transformación de la naturaleza por la acción del hombre. ${ }^{44}$ Una imagen del efecto de los monótonos paisajes cañeros la podemos ver en lo escrito en la década de 1830 sobre las impresiones de su paso por Guines por Jacinto de Salas y Quiroga, a quien sorprendió "aquel silencio sepulcral que por todas partes reinaba; raro pájaro cruzaba los aires, o se posaba sobre los árboles", para después afirmar: "Los aires nos parecieron despoblados, pero la tierra no nos lo pareció menos". 45

Mientras unas especies de plantas y animales se reducían o dejaban de existir, otras autóctonas o sobre todo exóticas se convirtieron en temidas plagas para el desarrollo de la agricultura y la ganadería. En el siglo XIX fue famosa la llamada yerba de Don Carlos, muy difícil de extirpar en los terrenos cultivados, y se mencionaba en el mismo sentido la yerba paraná, a pesar de ser uno de los mejores pastos artificiales para el ganado. Pero ningún caso es tan revelador como lo ocurrido en el siglo XX con el Marabú y demás plantas a las que se identifica con este nombre vulgar, que han invadido paulatinamente una extensión de tierras cada vez mayor, en especial las abandonadas por el cultivo y las

42 PICHARDO, Esteban, Diccionario provincial casi-razonado de vozes y frases cubanas, Ed. Ciencias Sociales, La Habana, 1985, p. 287. Esta edición parte de la cuarta edición corregida y aumentada, de 1875 [1836]. Escribió "En lo interior de la Isla hay muchas Guacamayas (como allá dicen a uno y otro sexo) y tan familiares que se dejan tirar a boca de jarro: es cosa peregrina ver un árbol ramoso matizado de tantos colores preciosos continuamente en movimiento, cubierto de innumerables y alborotadoras Guacamayas.

43 GUERRA, Félix, Los funerales del Rey. Ecología y fauna, Santiago de Cuba, Ed. Oriente, 1999, pp. 11-15.

44 Academia de Ciencias de Cuba, Nuevo Atlas Nacional de Cuba, 1989.

45 Viajes de Don Jacinto Salas y Quiroga, T. 1, Isla de Cuba, La Habana, Consejo Nacional de Cultura, 1964, p. 146-147. Primera edición Madrid, Boix Ed., 1840. 
dedicadas a la ganadería. Su forma de crecimiento en masas compactas dificulta su erradicación, sin que los métodos empleados para combatirla hayah ofrecido resultados definitivos. ${ }^{46}$

La relación de las implicaciones medioambientales de la transformación radical de la mayor parte de los paisajes cubanos en algo más de un siglo de crecimiento azucarero podría ser mucho más extensa. En cualquier caso resulta indiscutible que la enorme cantidad de materiales y nutrientes almacenados durante siglos en los bosques fueron un recurso fundamental para el gran esplendor azucarero de Cuba. Desde luego, no eran el único factor, basta mencionar la decisiva importancia de los esclavos africanos como fuerza de trabajo en las plantaciones. Pero se podría preguntar si el boom del azúcar hubiera sido posible sin maderas de construcción, abundante combustible y rendimientos agrícolas de ensueño. Algún día habrá que hacer el cálculo de cuánto de biodiversidad se consumió o esquilmó para abastecer las necesidades de alimentos de los nacientes centros industriales europeos y norteamericanos, enriqueciendo al poderoso grupo de los grandes hacendados en la isla, intereses colonialistas o a los accionistas extranjeros de los grandes latifundios azucareros.

Como es natural esa comparación tiene que hacerse en un contexto histórico determinado, pero no deja de tener sentido si se toman en cuenta valoraciones que alertaron en los mismos años sobre los peligros de dirigir todos los esfuerzos a la agricultura comercial. No faltaron contemporáneos que advirtieran sobre la falta de cultivos de subsistencia, la dependencia cada vez mayor del extranjero para obtener productos de primera necesidad, la acentuación de las desigualdades sociales, así como los efectos negativos en el orden ambiental. Este tipo de argumentos se mezcló muchas veces en el siglo XIX con la denuncia al sistema esclavista y su mentalidad de rapiña tanto con los seres humanos como con el medio. ${ }^{47}$ Si existía libertad para comerciar con negros esclavos, ¿por qué no iba a haberla para explotar los bosques? En este sentido no caben dudas de que el Decreto del 30 de agosto de 1815 potenció la idea de que el dueño podía disponer a su antojo de recursos que habían demorado siglos en formarse. Sobre la base de esta premisa, la creciente capacidad de las tecnologías de la era industrial para consumir y transformar los recursos naturales contribuyó a concretar el cambio paisajístico y ambiental más grande ocurrido en la historia de la presencia humana en la Isla de Cuba.

46 FUNES, Reinaldo, «El fin de los bosques y la plaga del marabú en Cuba. Historia de una venganza ecológica», Centro de Estudos de História do Atlantico, História e meio-ambiente. O impacto da expansao europeia, Actas do seminário internacional, Funchal, Madeira, 1999, pp. 369-392.

47 PÁDUA, José Augusto, Um Sopro de Destruição: Pensamento político e crítica ambiental no Brasil esclavista (1786-1888), Río de Janeiro, Jorge Zahar Editor, 2002. 